\title{
AVALIAÇÃO DA ACURÁCIA POSICIONAL PLANIMÉTRICA EM MODELOS DIGITAIS DE SUPERFÍCIE COM O USO DE FEIÇÕES LINEARES
}

\section{Planimetric positional accuracy assessment in digital surface models with the use of linear features}

\author{
Afonso de Paula dos Santos ${ }^{1}$ \\ Nilcilene das Graças Medeiros ${ }^{1}$ \\ Gérson Rodrigues dos Santos ${ }^{2}$ \\ Dalto Domingos Rodrigues ${ }^{1}$
}

\begin{abstract}
${ }^{1}$ Universidade Federal de Viçosa (UFV) - Dep. Eng. Civil - Setor de Eng. de Agrimensura e Cartográfica - Av. P.H. Rolfs., s/n, Campus Universitário, CEP 36570-900, Viçosa, Minas Gerais, Brasil.

2 Universidade Federal de Viçosa (UFV) - Dep. Estatística - Av. P.H. Rolfs., s/n, Campus Universitário, CEP 36570-900, Viçosa, Minas Gerais, Brasil.

afonso.santos@ufv.br; nilcilene.medeiros@ufv.br; gerson.santos@ufv.br; dalto@ufv.br;
\end{abstract}

\section{Resumo:}

Atualmente, tem-se aumentado a preocupação com a avaliação da acurácia posicional em dados espaciais, principalmente em dados com informações altimétricas. Contudo, vários trabalhos avaliam apenas a componente altimétrica, desconsiderando a acurácia posicional planimétrica. Assim, este trabalho tem como objetivo avaliar a acurácia posicional planimétrica dos principais MDSs disponíveis gratuitamente para o Brasil, como os modelos SRTM (banda C e X), Aster GDEM versão 2 e TOPODATA. Para a avaliação da acurácia posicional planimétrica dos MDSs, fez-se a extração de feições características do terreno como linhas de cumeadas e linhas de hidrografia numérica. Em seguida, de posse destas feições lineares, aplicou-se o método do Buffer Duplo para avaliar a acurácia posicional planimétrica de acordo com o padrão definido no Decreto-lei $\mathrm{n}^{\circ}$ 89.817/ET-ADGV. Para a comparação destes modelos, utilizou-se como referência um MDS, na escala de 1:25.000, obtido do sensor ALOS/PRISM. Os resultados da avaliação posicional planimétrica apresentaram Classe C na escala 1:100.000 para os MDS SRTM-X e Aster GDEM; para os MDS TOPODATA e SRTM-C, as classificações obtidas foram Classe B e Classe C na escala de 1:250.000, respectivamente.

Palavras-chave: Modelo Digital de Superfície, Acurácia Posicional, Feições Lineares.

\begin{abstract}
:
Currently, the concern over positional accuracy assessment in spatial data has grown, primarily in data with altimetric data information. However, several studies only assess the altimetric component, disregarding the planimetric positional accuracy. Thus, this work aims to evaluate the planimetric positional accuracy of the main MDSs available for free in Brazil, such as SRTM (band $\mathrm{C}$ and $\mathrm{X}$ ), Aster GDEM version 2 and TOPODATA models. To evaluate the planimetric positional accuracy ridge lines and numerical hydrography lines were extracted as terrain
\end{abstract}


characteristics. Then, in possession of these linear features, the Double Buffer method was applied to evaluate the horizontal accuracy according to the standards defined in Decree-Law ${ }^{\circ}$ 89,817/ET-ADGV. To compare these models an MDS obtained from ALOS/PRISM sensors, on a scale of 1:25,000, was used as a reference. The results of the planimetric positional evaluation were class $C$ at 1:100,000 scale for the MDS SRTM-X and Aster GDEM; for the MDS TOPODATA and SRTM-C, the obtained classifications were class B and class C on a scale of $1: 250,000$, respectively.

Keywords: Digital Surface Model, Positional Accuracy, Linear Features.

\section{Introdução}

Nos últimos tempos, tem-se observado um significativo aumento de sensores de mapeamento com a finalidade de permitir a extração de informações tridimensionais (Cruz et al., 2012). Assim como os sensores, a disponibilidade de hardwares e softwares cada vez mais robustos facilita a geração de produtos cartográficos, principalmente para a concepção de Modelos Digitais de Elevação (MDE) e de Superfície (MDS). As definições de tais modelos são apresentadas na seção 2 deste artigo.

Atualmente, na produção cartográfica em escalas médias e grandes de mapeamento, MDE/MDS são produzidos principalmente por Fotogrametria Digital e LiDAR (Höhle e Höhle, 2009). Os dois métodos são eficientes e acurados, obtendo uma alta densidade de pontos planialtimétricos. Quando se utilizam escalas de mapeamento pequenas, uma facilidade é a utilização de MDS disponíveis gratuitamente de forma global ou regional, como o SRTM, ASTER GDEM e o Topodata.

Sabe-se que a avaliação da acurácia posicional tridimensional de dados espaciais pode ser realizada, pelo menos, segundo dois modos diferentes (Li et al., 2005): (i) avaliar a acurácia posicional planimétrica e altimétrica separadamente e; (ii) utilizar uma medida única que avalie simultaneamente a acurácia planimétrica e altimétrica.

No controle de qualidade posicional de MDE/MDS, a avaliação da acurácia posicional planimétrica é negligenciada pela comunidade científica e profissional, sendo realizada apenas a avaliação da qualidade altimétrica isoladamente. De acordo com Höhle e Pedersen (2010), erros planimétricos de maior magnitude podem propagar e gerar erros altimétricos em áreas inclinadas. Ainda segundo os autores, métodos de levantamentos com sistemas de varredura a laser (LiDAR) normalmente apresentam discrepâncias posicionais planimétricas maiores do que as discrepâncias altimétricas.

São escassos os trabalhos de avaliação da acurácia posicional planimétrica em MDE/MDS, em formato matricial, de pequena e média escala. A maior parte dos trabalhos que avaliam a planimetria de MDS, utilizam dados LiDAR e normalmente são realizados em áreas urbanas com grande nível de detalhamento do MDS. Geralmente, em MDS provenientes de dados LiDAR, a análise da acurácia planimétrica é baseada nas discrepâncias das cumeeiras presentes em telhados de edificações. Maas (2002) obteve discrepâncias planimétricas por meio de uma correlação entre faixas de elevações sobrepostas; Vosselman (2008) comparou as distâncias entre as cumeeiras de telhados; Höhle e Pedersen (2010) obtiveram discrepâncias posicionais entre pontos de cumeeira de dados LiDAR, através de interseções de planos dos telhados, com pontos homólogos obtidos por Fotogrametria Digital; Ferreira (2014) comparou a distância entre bordas de edificações extraídas de dados LiDAR com dados de Fotogrametria Digital; Dresch e Santos (2014) propuseram um método que emprega simultaneamente superfícies planas, linhas retas e 
pontos para obtenção dos parâmetros de rotação e translação entre faixas adjacentes, fazendo uma avaliação da acurácia planialtimétrica interna do levantamento LiDAR.

Tachikawa et al. (2011) avaliaram a acurácia planimétrica de um MDS tomando como base um outro MDS de referência. Os autores reamostraram os MDSs para compartilharem da mesma resolução espacial e, após, estimaram as discrepâncias horizontais realizando um deslocamento do MDS avaliado nas direções X e Y sobre MDS de referência. Após, computou-se o desvio padrão das diferenças de altitude em cada deslocamento feito. Os deslocamentos $\mathrm{X}$ e $\mathrm{Y}$ associados ao menor valor de desvio-padrão foram expressos como a discrepância horizontal do MDS avaliado.

Nas últimas décadas, tem-se investigado a utilização de feições lineares no controle de qualidade posicional cartográfica, sendo desenvolvidos diversos métodos para avaliação da acurácia posicional. Santos et al. (2015) citam vários trabalhos que utilizaram e compararam tais métodos de feições lineares.

Segundo Santos et al. (2015), os métodos de avaliação da acurácia posicional com o uso de feições lineares consideram a comparação entre linhas homólogas dos dados de teste em relação aos dados de referência. Esta comparação analisa a razão entre comprimentos e quantidade de vértices, angularidade, razão de segmentos curvilíneos, distância entre os vértices, percentual de inclusão em uma área de influência, etc.

Escassos trabalhos utilizaram métodos de feições lineares para a avaliação da acurácia planimétrica em MDE/MDS, podendo ser citados os trabalhos de Reinoso (2011) e Mozas et al. (2013). Reinoso (2011) propõe avaliar a acurácia posicional planimétrica de um MDS utilizando a comparação de curvas de nível homólogas em outro MDS mais acurado. Mozas et al. (2013) obtém uma estimativa da acurácia planimétrica em MDS utilizando métodos de feições lineares em linhas de inclinação máxima entre duas curvas de nível.

De acordo com a fórmula de Koppe, as discrepâncias horizontais e verticais aumentam proporcionalmente à medida que a inclinação do terreno aumenta (Mozas et al., 2013). Assim a abordagem de linhas de cumeadas e linhas de hidrografia para análise planimétrica de um MDS, ao invés de curvas de nível, pode ser mais eficiente já que em uma única feição linear, normalmente, abrange diferentes altitudes e consequentemente diferentes níveis de inclinação do terreno.

Segundo Höhle e Höhle (2009), a quantidade de dados de elevação gerados pelos métodos atuais é enorme, enquanto que a avaliação da acurácia posicional é feita com poucos pontos de checagem, já que é bastante trabalhoso e oneroso obtê-los. Entretanto, deve-se ter uma amostra de checagem grande o suficiente para garantir uma avaliação confiável. Assim, o uso de feições lineares para a avaliação da acurácia posicional pode ser atraente, visto que com poucas feições lineares pode-se obter uma quantidade de informação e abrangência espacial similar quando se tem uma grande quantidade de pontos de checagem.

Diante do exposto, o objetivo deste trabalho é propor uma metodologia para avaliar a acurácia posicional planimétrica de Modelos Digitais de Superfície (MDS) com a utilização de feições lineares morfológicas do terreno, como linhas de cristas (cumeada) e talvegues (hidrografia numérica) ao invés da utilização de curvas de nível. Especificamente, avaliou-se a acurácia posicional planimétrica dos MDSs SRTM (banda C e X), Aster GDEM versão 2 e Topodata, aplicando o método Buffer Duplo utilizando como padrão de acurácia posicional brasileiro definido no Decreto-lei n ${ }^{\circ} 89.817$ aliada às Especificações Técnicas de Aquisição de Dados Geoespaciais Vetorias (ET-ADGV) da Infraestrutura Nacional de Dados Espaciais (INDE).

Bol. Ciênc. Geod., sec. Artigos, Curitiba, v. 22, no1, p.157 - 174, jan-mar, 2016. 


\section{Modelos Digitais de Superfícies}

Neste trabalho, adotou-se a definição de modelo digital do terreno (MDT), modelo digital de elevação (MDE) e modelo digital de superfície (MDS) de acordo com as definições propostas por Li et al. (2005):

- MDT: "Um MDT é um conjunto ordenado de pontos amostrais que representam a distribuição espacial de vários tipos de informação sobre o terreno". A expressão matemática de um MDT pode ser expressa em função das coordenadas planimétricas (Xp, Yp) de um ponto p, com o seu atributo K que representa alguma informação sobre o terreno no ponto $\mathrm{p}$ (Equação 01).

$$
K=f(X p, Y p)
$$

Percebe-se que o termo MDT é genérico, sendo utilizado para diversos atributos do terreno, como inclinação, temperatura, pluviosidade, geologia, entre outros.

- O termo MDE é caracterizado como uma particularização do MDT, onde o atributo $K$ representa a altitude do terreno. É um modelo que representa a superfície do terreno imersa ou emersa sem cobertura vegetal ou edificações;

- Já o termo MDS é utilizado para modelos que consideram as elevações do terreno e de qualquer objeto acima dele, como edificações e cobertura vegetal.

\subsection{Principais MDSs disponíveis}

Atualmente encontram-se disponíveis diversos MDSs com abrangência global ou regional, proporcionando uma diversidade de aplicações. Exemplos destes modelos são:

SRTM (Shuttle Radar Topographic Mission): missão realizada em conjunto pela agência espacial norte-americana (NASA), o Departamento de Defesa dos Estados Unidos da América, representado pela National Geospatial-Intelligence Agency (NGA), a Agência Espacial Alemã (DLR) e Agência Espacial Italiana (ASI), durante o mês de fevereiro de 2000. O objetivo da missão SRTM era adquirir um MDE entre as latitudes $60^{\circ} \mathrm{N}$ a $56^{\circ} \mathrm{S}$ cobrindo, assim, $80 \%$ da superfície continental do globo terrestre. Para realização de tal levantamento, foram utilizados dois radares de abertura sintética (SAR) por interferometria (InSAR): um dos sistemas continha a banda $\mathrm{X}$, com resolução espacial de 1 segundo de arco ( $\sim 30 \mathrm{~m}$ no equador); o outro contendo a banda $\mathrm{C}$, dispondo de uma resolução de 3 segundos de arco ( $90 \mathrm{~m}$ no equador), sendo ambos os sistemas referenciados ao sistema geodésico WGS84 e ao modelo geoidal EGM96, para a representação da altitude ortométrica. De forma geral, o SRTM possui uma acurácia vertical absoluta de cerca de 16 metros para a banda $\mathrm{C}$ e de 6 metros para a banda $\mathrm{X}$, a acurácia planimétrica absoluta é da ordem de 20 metros na banda $\mathrm{C}$ e 15 metros para a banda X, utilizando um nível de confiança de 90\%, de acordo com a National Map Accuracy Standard (NMAS) (Farr et al., 2007; DLR, 2015).

ASTER GDEM (Advanced Spaceborne Thermal Emission and Reflection Radiometer - Global Digital Elevation Model): o ASTER GDEM foi concebido através de uma parceria entre o Ministério de Economia, Industria e Comércio do Japão (METI) e a Agência Espacial NorteAmericana (NASA). Para gerar um MDS que englobasse $99 \%$ da área continental do planeta, latitude $83^{\circ} \mathrm{N}$ a $83^{\circ} \mathrm{S}$, utilizaram-se imagens estereoscópicas obtidas do sensor ASTER presente no satélite TERRA entre os anos de 2000 e 2010. O MDS gerado apresenta resolução espacial de 1 segundo de arco ( $\sim 30 \mathrm{~m}$ no equador), está referenciado ao sistema geodésico WGS84 e 
associado ao modelo geoidal EGM96. O modelo GDEM, versão 2, possui uma acurácia planimétrica absoluta da ordem de 6 metros e uma acurácia vertical absoluta de cerca de 12 metros (Tachikawa et al., 2011).

TOPODATA: este projeto consistiu em uma derivação do modelo SRTM, refinando a resolução espacial de 3 arco de segundos para 1 arco de segundo, a partir da interpolação por Krigagem e, após, realizando várias derivações geomorfológicas. Não se deve esperar que o refinamento apresente uma melhora na qualidade posicional, mas sim favorecer uma melhor percepção de feições relativamente detalhadas (Valeriano, 2008). Entretanto, Miceli et al. (2011) realizaram a avaliação da acurácia altimétrica dos modelos SRTM banda C, ASTER versão 1 e TOPODATA na região amazônica e em Petrópolis-RJ, obtendo como resultado uma melhor acurácia vertical do TOPODATA em relação aos outros modelos.

\subsection{O problema da avaliação da acurácia posicional em MDS}

Segundo Ariza et al. (2004), há basicamente duas maneiras de estudar a acurácia posicional em uma base cartográfica: através da análise do processo de produção e pela avaliação do produto. A acurácia posicional pelo processo é uma forma que consiste em estudar toda cadeia produtiva, entendendo e quantificando as discrepâncias em cada operação cartográfica e, ao final, obtém-se uma estimativa geral da discrepância da produção cartográfica. Já a segunda forma, acurácia posicional pelo produto, consiste em comparar o produto cartográfico final, mediante testes estatísticos, com uma amostra de dados de referência.

Percebe-se que esta última forma é a mais utilizada para avaliar a qualidade posicional de dados espaciais. As normas e padrões existentes de avaliação da acurácia posicional englobam esta forma estatística, definindo métodos e tolerâncias para avaliar a qualidade posicional dos dados espaciais. Assim, para aplicar testes estatísticos, utiliza-se uma amostra de dados de checagem que pode ser uma amostra de feições pontuais ou uma amostra de feições lineares. Quanto aos componentes posicionais a serem avaliados, estes podem ser bidimensionais ou planimétricos $(2 \mathrm{D}-\mathrm{X}$ e $\mathrm{Y})$ e tridimensionais ou planialtimétricos (3D - X, Y e Z).

A avaliação posicional planimétrica em dados espaciais é bem difundida e tradicional, podendo ser verificada pelos vários métodos existentes que se utilizam de feições pontuais e/ou lineares.

Conforme dito anteriormente, a avaliação da acurácia posicional tridimensional de dados espaciais pode ser realizada, pelo menos, segundo duas técnicas diferentes: (1) avaliar a acurácia posicional planimétrica e altimétrica separadamente e; (2) utilizar uma medida única que avalie simultaneamente a acurácia planimétrica e altimétrica.

A Figura 1 apresenta um exemplo tradicional da avaliação de um MDE/MDS. Ao contrário da avaliação de uma base cartográfica ou uma imagem orbital, onde se têm feições cognitivas e homólogas tanto no objeto de avaliação quanto no mundo real, em um MDE/MDS, na maioria das vezes, não há uma feição característica que seja bem definida e de fácil reconhecimento em campo. Portanto, na maioria dos casos, o técnico responsável pela avaliação do MDE/MDS coleta os dados de checagem em locais bem definidos em campo, como o cruzamento de uma estrada ou a quina de um lote, embora não tenha como reconhecer este mesmo ponto em um MDE/MDS. Neste caso, a avaliação (Figura 1.a) é realizada desconsiderando a componente planimétrica, ou seja, considera-se acurada a planimetria do MDE/MDS, restando apenas a avaliação pontual da altimetria. Assim, tem-se que a localização X e Y do ponto de checagem (círculo) é o mesmo do ponto correspondente no MDE/MDS (estrela); logo, a avaliação da acurácia deste MDE/MDS apenas considera as discrepâncias entre a coordenada Z. Na Figura 1.b é apresentada a avaliação conjunta da planimetria e altimetria no MDE/MDS, ou seja,

Bol. Ciênc. Geod., sec. Artigos, Curitiba, v. 22, no1, p.157 - 174, jan-mar, 2016. 
considera a posição correspondente do ponto de checagem no MDE/MDS, assim obtém-se a medida de acurácia posicional avaliando as componentes planimétrica e altimétrica.

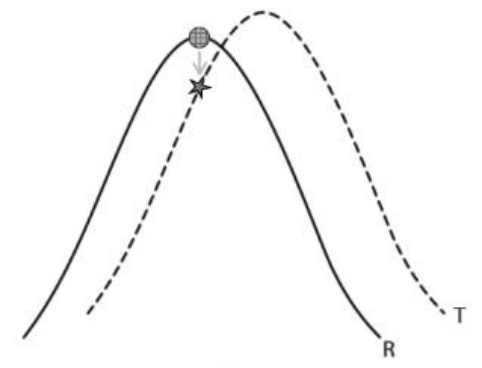

(a)

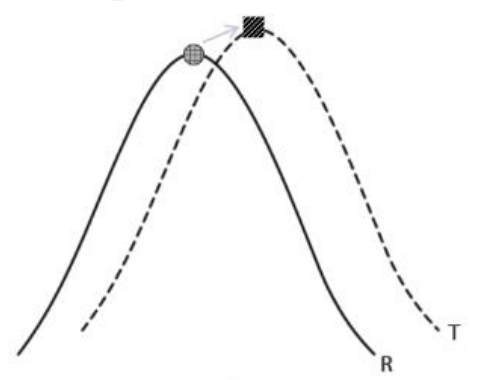

(b)

Figura 1: Avaliação da acurácia posicional de um MDE/MDS. No caso (a) a avaliação da acurácia posicional é realizada apenas verticalmente de modo errôneo, no caso (b) a avaliação da acurácia posicional é realizada considerando a planimetria e altimetria.

\section{Avaliação da acurácia posicional planimétrica em MDE/MDS com o uso de feições lineares}

Diante do problema exposto no item anterior, sugere-se, para avaliação da acurácia posicional em um MDE/MDS, utilizar feições morfológicas do terreno como linhas de talvegues e cristas, caracterizadas pela rede hidrográfica e pelas linhas de cumeadas, respectivamente.

As linhas de cumeadas do terreno representam as linhas que unem os pontos mais altos de uma sequência de morros e montanhas. A determinação destas linhas de cumeada se caracteriza como sendo o limite da bacia de contribuição de cada segmento de hidrografia. Este segmento pode ser o trecho de hidrografia compreendido da nascente a uma confluência, entre duas confluências ou entre uma confluência e a foz da rede hidrográfica (Ribeiro et al., 2005).

O termo hidrografia numérica utilizado neste trabalho consiste no conjunto de linhas que definem a drenagem numérica derivada de MDE/MDS. Assim, estas linhas representam os locais preferenciais de escoamento das águas superficiais.

$\mathrm{Na}$ metodologia proposta, visa-se a avaliação relativa da acurácia posicional planimétrica de um MDE/MDS. Portanto, é necessário um MDE/MDS de referência, que seja comprovadamente mais acurado que o MDE/MDS a ser testado.

Em ambos os modelos, extraem-se a hidrografia numérica e as linhas de cumeada do terreno, conforme procedimento descrito no item 5.3.2. Após, seleciona-se uma amostra de linhas homólogas (Figura 2) neste conjunto de linhas de hidrografia numérica e linhas de cumeada, em ambos MDE/MDS, de teste e de referência. De posse da amostra de feições lineares homólogas aplicam-se métodos de avaliação da acurácia posicional baseados em feições lineares associada a uma norma ou padrão de acurácia posicional.

Um ponto importante na avaliação de um MDS é comparar as linhas de cumeada e de hidrografia numérica gerada. Se este conjunto de linhas não for coerente, tendo o formato e níveis de detalhes similares com o conjunto de linhas extraídos do MDS de referência, pode-se inferir antecipadamente que o MDS testado não possui uma boa acurácia posicional planimétrica e altimétrica.

Pode-se pensar que a própria extração de linhas de cumeadas e de hidrografia numérica possa inserir erros no processo de avaliação da acurácia posicional. Entretanto, o mesmo procedimento de extração de feições características do terreno é aplicado tanto ao modelo a ser avaliado quanto ao modelo de referência utilizado no processo de avaliação da acurácia posicional, conforme 
seção 5.3.2. Assim, caso exista algum erro sistemático no processo de extração destas feições lineares, este mesmo erro será inserido tanto nas linhas de teste quanto nas linhas de referência. Ao calcular as discrepâncias posicionais entre as linhas (que é a base para avaliação da acurácia posicional), este possível erro sistemático não existirá, não afetando, portanto, o processo de avaliação do MDS. Entretanto, pode-se ter outra influência neste processo no que tange às resoluções espaciais dos modelos utilizados. Se os modelos utilizados na avaliação da acurácia posicional apresentarem resolução espacial incompatível com a escala de uso indicada, o processo de conversão raster/vetor das linhas de cumeada e hidrografia numérica pode influenciar o processo de avaliação da acurácia posicional.

Quando se compara esta metodologia proposta com o método utilizado por Tachikawa et al. (2011), percebe-se uma maior eficiência na aplicabilidade da metodologia, já que não é necessário realizar uma reamostragem dos MDS e nem transladar repetidamente um MDS sobre o outro. Quanto aos métodos utilizados na avaliação da acurácia planimétrica em MDS obtidos por LiDAR, esta metodologia pode ser atrativa quando se trabalha em regiões não-urbanas, onde não se tem tantos detalhes de telhados de casas. Já quando se compara com a avaliação baseada no uso de curvas de nível, a abordagem de linhas de cumeadas e linhas de hidrografia pode ser mais interessante, já que em uma única feição abrange diferentes altitudes e consequentemente diferentes níveis de inclinação do terreno.

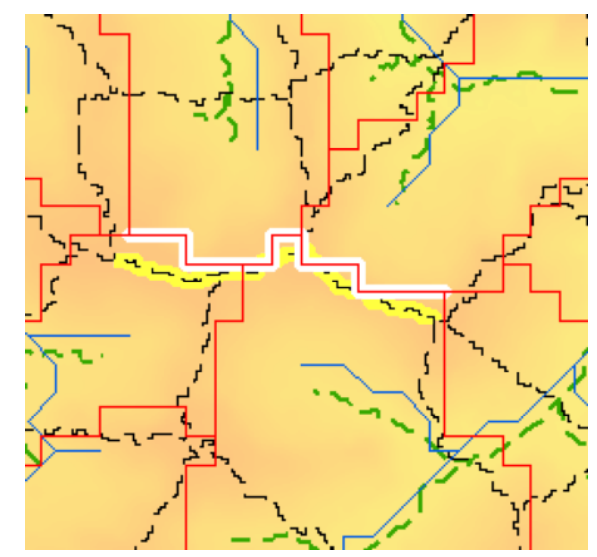

Figura 2: Linhas homólogas (com fundo em branco e amarelo) utilizadas para avaliação da acurácia posicional planimétrica em MDS. O MDS de teste apresenta as linhas de cumeadas em vermelho e hidrografia numérica em azul. O MDS de referência apresenta linha de cumeada em preto tracejado e hidrografia numérica em verde tracejado.

\section{Controle de qualidade posicional utilizando feições lineares}

No Brasil, para a classificação da acurácia posicional planimétrica de um produto cartográfico utiliza-se o padrão descrito no Decreto-lei 89.817 aliada à ET-ADGV. Para seu enquadramento, deve-se obedecer a duas condições (BRASIL, 1984; Santos, 2010; DSG, 2011): (i) 90\% dos valores de discrepâncias posicionais devem ser iguais ou inferiores ao valor do PEC em relação à escala e a classe testada e; (ii) o RMS (root mean square) das discrepâncias deve ser igual ou inferior à tolerância EP definido pela norma (Tabela 1). 
Tabela 1: Tolerâncias planimétricas utilizadas no padrão do Decreto-lei 89.817/ET-ADGV.

\begin{tabular}{c|c|c|c|c|c|c}
\hline \multirow{2}{*}{ Classe } & \multicolumn{2}{|c|}{ Planimetria } & \multicolumn{2}{c|}{ Esc. 1:100.000 } & \multicolumn{2}{c}{ Esc. 1:250.000 } \\
\cline { 2 - 7 } & PEC $^{*}$ & EP* & PEC & EP & PEC & EP \\
\hline $\mathbf{A}$ & $0,28 \mathrm{~mm}$ & $0,17 \mathrm{~mm}$ & $28 \mathrm{~m}$ & $17 \mathrm{~m}$ & $70 \mathrm{~m}$ & $42,5 \mathrm{~m}$ \\
\hline $\mathbf{B}$ & $0,5 \mathrm{~mm}$ & $0,3 \mathrm{~mm}$ & $50 \mathrm{~m}$ & $30 \mathrm{~m}$ & $125 \mathrm{~m}$ & $75 \mathrm{~m}$ \\
\hline $\mathbf{C}$ & $0,8 \mathrm{~mm}$ & $0,5 \mathrm{~mm}$ & $80 \mathrm{~m}$ & $50 \mathrm{~m}$ & $200 \mathrm{~m}$ & $125 \mathrm{~m}$ \\
\hline $\mathbf{D}$ & $1,0 \mathrm{~mm}$ & $0,6 \mathrm{~mm}$ & $100 \mathrm{~m}$ & $60 \mathrm{~m}$ & $250 \mathrm{~m}$ & $150 \mathrm{~m}$ \\
\hline
\end{tabular}

* PEC e EP são tolerâncias do padrão de acurácia descrito pelo Decreto-lei n ${ }^{\circ} 89.817$, sendo denominados por Padrão de Exatidão Cartográfica e Erro Padrão, respectivamente.

Santos et al. (2015) descreveram metodologicamente a aplicação dos métodos de avaliação da acurácia posicional planimétrica através de feições lineares da Banda Épsilon (Método das Áreas), Buffer Simples, Buffer Duplo, Distância de Hausdorff e Influência do Vértice; utilizando como padrão o Decreto-lei $n^{\circ}$ 89.817. Os autores aplicaram tais métodos na avaliação de uma ortoimagem Ikonos, através da comparação de linhas homólogas caracterizadas por estradas vicinais e rodovias. Como resultado, foi constatada a viabilidade de utilização de feições lineares associado ao padrão de acurácia do Decreto-lei 89.817, além de perceberem que o método do Buffer Duplo apresentou resultados similares ao método tradicional de avaliação que utiliza-se de feições pontuais, percebendo que estes são mais rigorosos que os demais.

O método do Buffer Duplo, também chamado de Buffer Overlay Statistics e criado por Tveite e Langaas (1999), consiste em aplicar o modelo da Banda de Erro tanto na linha de referência quanto na linha a ser testada.

O modelo de faixa de incerteza ou Banda de Erro é uma faixa ao redor da posição de referência (tida como a posição mais provável) de uma feição espacial. O modelo da faixa de incerteza consiste em gerar um buffer ao redor do segmento de linha, sendo esta área utilizada para representar a incerteza posicional da feição linear.

Portanto, no método do Buffer Duplo aplica-se um buffer em ambas as linhas, e em seguida é realizada uma interseção entre os polígonos resultantes dos buffers (Figura 3), de modo a obter uma medida de discrepância média (equação 02) entre as feições lineares. Assim, é possível avaliar posicionalmente a acurácia do dado espacial em teste.

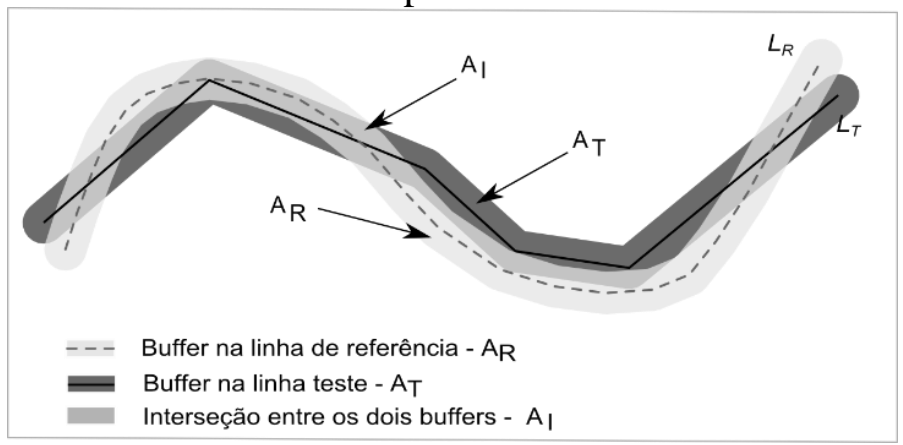

Figura 3: Método do Buffer Duplo para avaliação da acurácia posicional.

Segundo Santos et al. (2015), para a aplicação do Buffer Duplo associado ao Decreto-lei 89.817, utilizam-se as seguintes etapas:

1. Selecionar uma amostra de $n$ linhas homólogas de teste $\left(L_{T}\right)$ e de referência $\left(L_{R}\right)$;

2. Aplicar um buffer de tamanho $x$ em cada linha $i$ da amostra de linhas homólogas de teste e referência. Para o emprego do Decreto-lei no 89.817, utiliza-se como tamanho do buffer o valor do PEC para a escala e a classe utilizada no processo de avaliação;

3. Calcular a área $A_{T}$ gerada pela operação de buffer em cada linha de teste. 
4. Fazer uma sobreposição entre os polígonos gerados pelos buffers da linha teste e da linha de referência e calcular o valor de $A_{F}$, referente a área do polígono de referência que não faz interseção ao polígono teste;

5. Calcular a discrepância média $(d m)$, para cada linha teste $i$ (equação 2);

$$
d m_{i}=\pi \cdot x \cdot \frac{\left(\sum A_{F}\right)_{i}}{A_{T_{i}}}
$$

6. Para classificação do produto quanto ao Decreto-lei $\mathrm{n}^{\circ} 89.817 / \mathrm{ET}-\mathrm{ADGV}$ faz-se uma adaptação das condições originais deste: verifica-se a normalidade dos dados e, se constatada, faz-se a análise se $90 \%$ das linhas testadas apresentam discrepâncias médias $(\mathrm{dm})$ menores ou iguais ao valor do PEC (da classe e escala utilizados para gerar o buffer $x$ ), e ainda, o RMS das discrepâncias médias $(d m)$ deve ser menor ou igual ao valor do EP (idem ao PEC). Se as duas condições forem satisfeitas, classifica-se o dado espacial de acordo com a classe e a escala trabalhada.

\section{Experimento Prático}

\section{1 Área de Estudo}

A área de estudo deste trabalho está compreendida na região de Viçosa-MG, abrangendo 9 municípios, com seus limites delimitados pelas latitudes $20^{\circ} 45^{\prime} \mathrm{S}$ e $21^{\circ} \mathrm{S}$, e longitudes $42^{\circ} 45^{\prime} \mathrm{W}$ e $43^{\circ} \mathrm{W}$, conforme Figura 4 . A região apresenta relevo montanhoso, com altitudes variando de 330 a 970 metros; uma área de cerca de $760 \mathrm{~km}^{2}$ e; está inserida na divisa entre duas bacias hidrográficas, sendo elas: rio Doce e rio Paraíba do Sul.

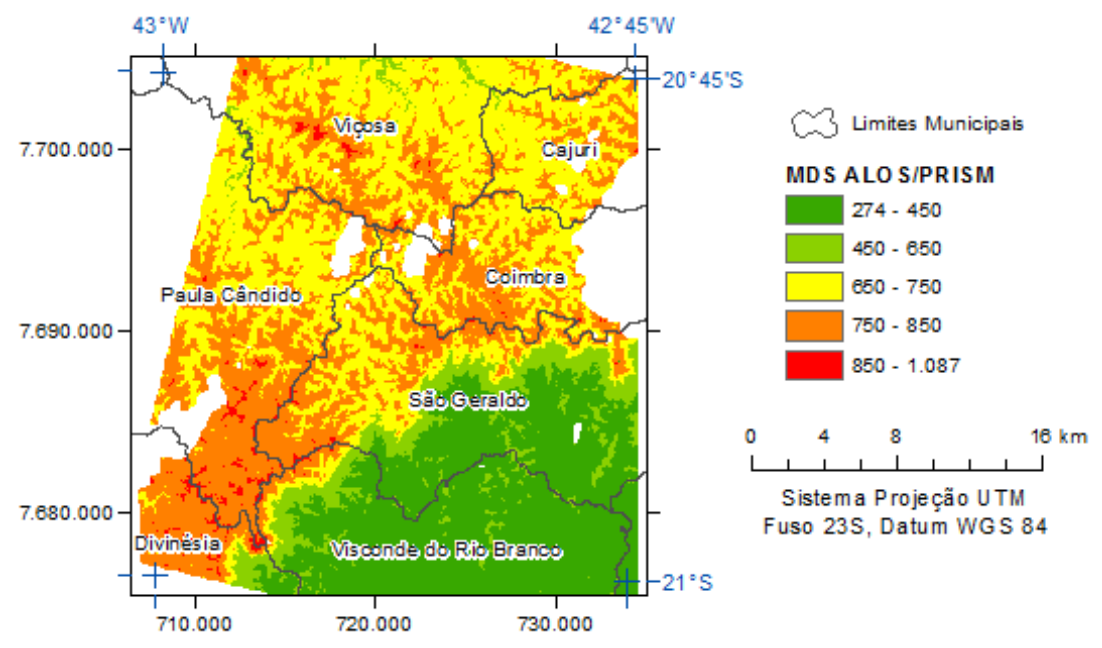

Figura 4: Área de estudo. 


\subsection{Materiais utilizados}

Os materiais utilizados neste trabalho foram:

- Modelo Digital de Superfície SRTM (Shuttle Radar Topographic Mission), banda C, com resolução espacial de 90 metros, versão 4.1, disponibilizado gratuitamente pela CGIARCSI (Consultative Groupon International Agricultural Research - Consortium for Spatial Information);

- Modelo Digital de Superfície SRTM, banda X com resolução espacial de 30 metros, disponibilizado gratuitamente pela Agência Aeroespacial Alemã DLR (Deutschen Zentrums für Luft- und Raumfahrt);

- Modelo Digital de Superfície ASTER GDEM (Global Digital Elevation System), com resolução espacial de 30 metros, versão 2, disponibilizado gratuitamente pela NASA através do sistema EOSDIS (Earth Observing System Data Information System);

- Modelo Digital de Superfície TOPODATA, com resolução espacial de 30 metros, disponibilizado gratuitamente pela INPE (Instituto Nacional de Pesquisas Espaciais);

- Modelo Digital de Superfície ALOS/PRISM, com 10 metros de resolução espacial, datum horizontal e vertical WGS84, altitude elipsoidal, com acurácia posicional altimétrica Classe A na escala 1:25.000 (Decreto-lei ${ }^{\circ}$ 89.817), obtido do trabalho de EGG (2012). Este mesmo MDS foi utilizado para a ortorretificação da imagem PRISM, sendo obtido a classificação planimétrica Classe A na escala 1:25.000.

- Software ArcGIS10.2, para manipulação dos dados espaciais e aplicação dos métodos testados.

- Software F447, para obtenção da ondulação geoidal no modelo EGM96. Disponibilizado pelas agências norte-americanas NGA e NASA.

- Software R, para inferência estatística da normalidade da amostra de discrepância posicional.

\subsection{Metodologia}

Para a execução deste trabalho, três etapas foram necessárias: (i) pré-processamento dos MDSs; (ii) extração de feições lineares dos MDSs e; (iii) avaliação da acurácia posicional planimétrica dos MDSs.

\subsubsection{Pré-processamento dos MDSs}

Esta etapa consistiu-se da homogeneização dos referenciais espaciais dos MDS testes (SRTM-C, SRTM-X, GDEM e TOPO) e do MDS de referência (ALOS/PRISM). Originalmente, os modelos testes estavam referenciados a altitude ortométrica com modelo geoidal EGM96, já o modelo de referência estava referenciado a altitude elipsoidal. 
Para uniformização dos dados, os referenciais altimétricos foram convertidos para altitude elipsoidal. Assim, gerou-se uma malha de pontos com espaçamento de 200m, na área de estudo, para obtenção da ondulação geoidal pelo modelo EGM96, utilizando o software F447. Após, estes dados foram utilizados para gerar um arquivo matricial, de resolução espacial igual aos modelos testes $(30 \mathrm{~m}$ e $90 \mathrm{~m})$, onde cada pixel contêm o valor da ondulação geoidal do modelo EGM96. Para a geração do arquivo matricial, foi empregado o interpolador do Vizinho Natural (Natural Neighbor) que utiliza pesos obtidos através das áreas proporcionais dos polígonos de Voronoi (Thiessen) vizinhos ao ponto não-amostrado (Sibson, 1981). Este interpolador cria uma superfície contínua sem picos, depressões, cristas ou vales.

Conhecendo a ondulação geoidal da região, foram obtidos os MDSs em altitude elipsoidal (h) para os modelos GDEM2, SRTM-X, SRTM-C e TOPODATA. Para realizar tal tarefa, fez-se uma operação de adição de imagens: o MDS original, em altitude ortométrica $(H)$, foi somado com a imagem da ondulação geoidal $(\mathrm{N})$, conforme a equação 03.

$$
h=H+N
$$

\subsubsection{Extrações de feições lineares dos MDSs}

Para a aplicação do método de avaliação da acurácia posicional baseado no uso de feições lineares, utilizou-se da comparação de um conjunto de feições morfológicas do terreno, como linhas de cristas (cumeada) e linhas de talvegue (hidrografia numérica), extraídos dos diferentes MDS utilizados.

Para a extração da hidrografia numérica e linhas de cumeadas nos modelos, aplicou-se o processo apresentado pela Figura 5. O primeiro passo consiste em verificar a consistência do MDE quanto à presença de depressões espúrias, visando obter a direção de fluxo do MDE através do algoritmo das oito direções (D8). Esse algoritmo estima as direções de fluxo para cada célula do MDE com a análise de uma janela móvel de tamanho 3x3, em que se considera a maior inclinação de seus vizinhos (Fernández et al., 2012). De acordo com a direção da célula da qual resulta a maior inclinação, é atribuído um valor numérico à célula em análise. Portanto, se a imagem proveniente da aplicação da direção de fluxo apresentar mais do que oito valores numéricos distintos, constata-se que o modelo não está consistente, existindo a presença de depressões espúrias. Se o modelo apresentar depressões espúrias, faz-se a correção, preenchendo-as de modo que todo o fluxo do modelo consiga escoar à foz de sua bacia hidrográfica.

Em seguida, com o modelo consistente aplica-se novamente o algoritmo para a extração da direção de fluxo. Após, obtém-se o fluxo acumulado para cada célula do modelo; logo, como resultado, será gerada uma imagem onde cada célula terá um número que corresponde à quantidade de células a montante que contribui com o escoamento que passa pela célula em análise. Logicamente que para a extração do fluxo acumulado é necessário o uso da direção de fluxo do modelo para a análise de qual célula está a montante ou jusante.

Segundo Fernández et al. (2012), o método mais comum para a extração da hidrografia numérica é a estimativa da área de captação. Portanto, realizando uma prévia análise sobre a rede hidrográfica presente na região de estudo, percebeu-se que os cursos d'água começam a ser formados (ou mapeados) em torno de 10ha de área de contribuição. Como os modelos GDEM2, TOPO, SRTM-X e SRTM apresentam resoluções espaciais de 30, 30, 30 e 90 metros 
respectivamente, para que uma célula nos modelos seja considerada um curso d'água, esta teria que ter valores iguais ou superiores de fluxo acumulado de 112,112, 112 e 13, obtendo uma área de acumulação de pouco mais de 10ha. Feita esta reclassificação e convertendo as células consideradas como cursos d'água para o formato vetorial, sem considerar qualquer processo de simplificação geométrica, obtém-se a hidrografia numérica.

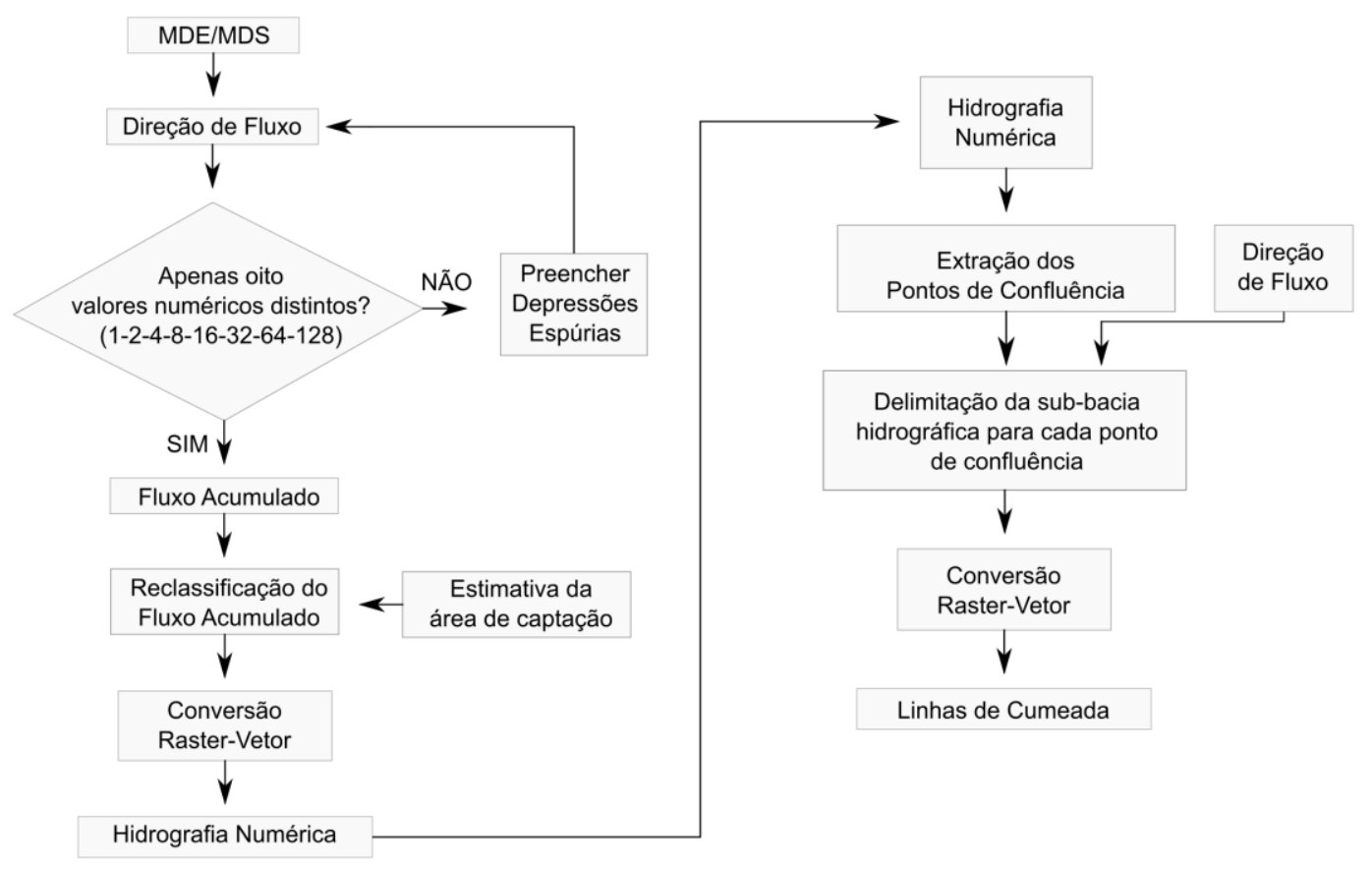

Figura 5: Processo utilizado para extração da hidrografia numérica e linha de cumeada a partir de um MDS.

Para obtenção das linhas de cumeadas, extraem-se os vértices da rede hidrográfica que se caracterizam como pontos de confluência, ou seja, o último vértice de trecho de hidrografia. Após, calcula-se a bacia de acumulação para cada confluência. As delimitações das bacias de acumulação em formato matricial são convertidas para o formato vetorial em polígonos. A linha de cumeada se caracteriza por ser as linhas dos limites dos polígonos da bacia de acumulação obtidas para cada ponto de confluência.

\subsubsection{Avaliações da acurácia planimétrica dos MDSs}

A avaliação da acurácia posicional planimétrica dos MDSs GDEM2, SRTM-C, SRTM-X e TOPODATA utilizou um conjunto de linhas homólogas ao MDS ALOS/PRISM que serviu como referência. As escalas de teste foram 1:100.000 e 1:250.000.

De posse das linhas de hidrografias numéricas e linhas de cumeadas em todos os modelos, utilizou uma amostragem estratificada não-aleatória. Por este motivo, a região de estudo foi dividida em quadrantes de $2 \times 2$ quilômetros para que em cada quadrante fosse selecionado um trecho de linha de cumeada, e quadrantes de 4x4 quilômetros, para a coleta de linhas de hidrografia numérica.

Para a escolha do trecho a ser selecionado, tanto para hidrografia quanto para linha de cumeada, foram definidas algumas estratégias, como: (1) não conter trecho de nascente, de modo a não influenciar a diferença entre as áreas de acumulação da linha de referência e da linha de teste; (2) conter trechos dispostos entre confluências hidrográficas ou interseções de linhas de cumeadas 
bem definidas nos modelos; (3) não conter trechos em que houvesse a presença de massas d'água, como rios largos, lagoas e represas; (4) selecionar pequenos e grandes trechos em comprimento.

Ao todo, foram coletadas 136 linhas de cumeadas e 40 linhas de hidrografia numérica homólogas em cada MDS, totalizando 176 linhas (ver Figura 6).

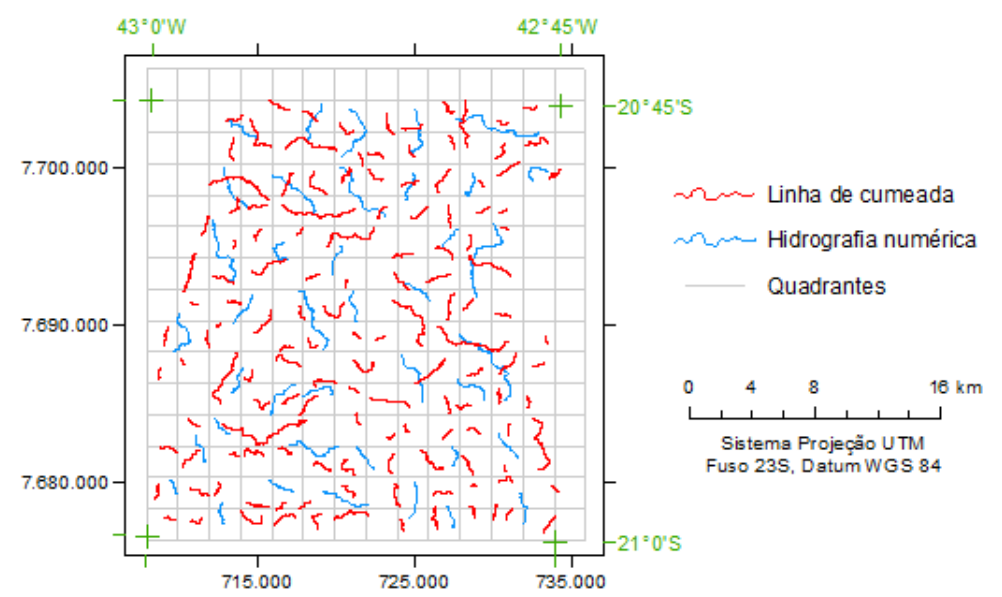

Figura 6: Feições lineares utilizadas para a avaliação da acurácia posicional planimétrica dos MDSs.

É importante frisar que não há consenso na comunidade científica acerca do número de elementos em uma amostra de checagem utilizada no controle de qualidade cartográfica, principalmente na abordagem por feições lineares, sendo este assunto carente de pesquisas.

De posse do conjunto de linhas homólogas selecionadas nos modelos, aplicou-se o método de avaliação da acurácia posicional Buffer Duplo empregando o padrão de acurácia posicional do Decreto-lei 89.817/ET-ADGV. O método do Buffer Duplo foi implementado no software ArcGIS utilizando a ferramenta Model Builder.

Após a utilização do Buffer Duplo, obtém-se uma amostra de discrepâncias posicionais planimétricas. De posse destes dados, foi aplicada a detecção de outliers utilizando o diagrama Boxplot. Este diagrama utiliza as estatísticas descritivas da mediana, primeiro e terceiro quartil (Q1 e Q3). A subtração entre Q3 e Q1 é chamada de interquartil (IQR). Para a detecção de outliers utilizam-se o limiar inferior e superior, que são apresentados pelas equações 04 e 05 (Montgomery e Runger, 2002).

$$
\begin{aligned}
& \text { Limiar }_{\text {superior }}=Q 3+1,5 \cdot I Q R \\
& \text { Limiar }_{\text {inferior }}=Q 1-1,5 \cdot I Q R
\end{aligned}
$$

Valores de discrepâncias posicionais acima de Q3 somados à multiplicação da constante 1,5 pelo IQR; e valores abaixo do Q1 subtraídos da multiplicação da constante 1,5 pelo IQR são considerados outliers e devem ser investigados. Se esta verificação não descobrir quaisquer erros de manipulação ou seleção das linhas homólogas, estas feições devem ser retiradas da análise de acurácia posicional. Caso for verificado algum erro de manipulação ou seleção deve-se corrigir a amostra de checagem, sendo reprocessado novamente as linhas homólogas pelo método do Buffer Duplo.

A construção de um diagrama Boxplot é realizada criando uma caixa em que a borda inferior é o valor de Q1 e o limite superior o valor de Q3, sendo que uma linha de maior espessura dentro da caixa se caracteriza pela representação do valor da mediana. Valores classificados como outliers 
são apresentados por círculos acima da linha que representa o último valor de discrepância anterior ao limiar inferior ou superior de detecção de outliers.

Não constatada a presença de outliers ou feita sua retirada, infere-se sobre a normalidade da amostra de discrepâncias. Para esta etapa, utilizou-se o teste de Shapiro-Wilk, em ambiente R.

Verificado que a amostra de discrepâncias posicionais planimétricas segue a distribuição normal, é aplicada a avaliação da acurácia posicional planimétrica utilizando o Decreto-lei 89.817/ETADGV, conforme item 4. Ao final, os MDS testados são classificados quanto à acurácia posicional planimétrica.

\section{RESULTADOS}

Como descrito na seção 4, a aplicação do método do Buffer Duplo depende da tolerância do PEC, que está relacionado com a classe e a escala testada, para utilizá-la como largura do buffer. Ao utilizar um determinado valor para a largura do buffer, deve-se aplicar, por analogia, o Decreto-lei 89.817 apenas para a classe e escala correspondentes a esta tolerância utilizada na largura do buffer. Se a classificação não for aceita, utiliza-se o Buffer Duplo com outra tolerância PEC, gerando uma outra amostra de discrepância.

Na aplicação do método do Buffer Duplo para avaliação da acurácia posicional planimétrica dos MDSs, testou-se todas as classes do padrão Decreto-lei 89.817 para a escala de 1:100.000 e 1:250.000. As tolerâncias de $80 \mathrm{~m}, 80 \mathrm{~m}, 125 \mathrm{~m}$ e $200 \mathrm{~m}$ foram utilizadas respectivamente para a aplicação do Buffer Duplo nos MDSs SRTM-X, GDEM2, TOPODATA e SRTM-C.

De posse da amostra de discrepâncias posicionais planimétricas de cada MDS, foi aplicada a detecção de outliers via Boxplot (ver Figura 7). Nos MDSs SRTM-X e GDEM2 foram detectados 14 outliers, com limiar de $68 \mathrm{~m}$ e $84 \mathrm{~m}$, respectivamente. No MDS TOPODATA foram detectados 5 outliers, sendo o limiar da ordem de $132 \mathrm{~m}$. Para o MDS SRTM-C, detectaram-se 9 outliers, sendo o limiar da ordem de 184m. A Tabela 2 apresenta as estatísticas básicas da amostra de discrepâncias posicionais após a retirada dos outliers.

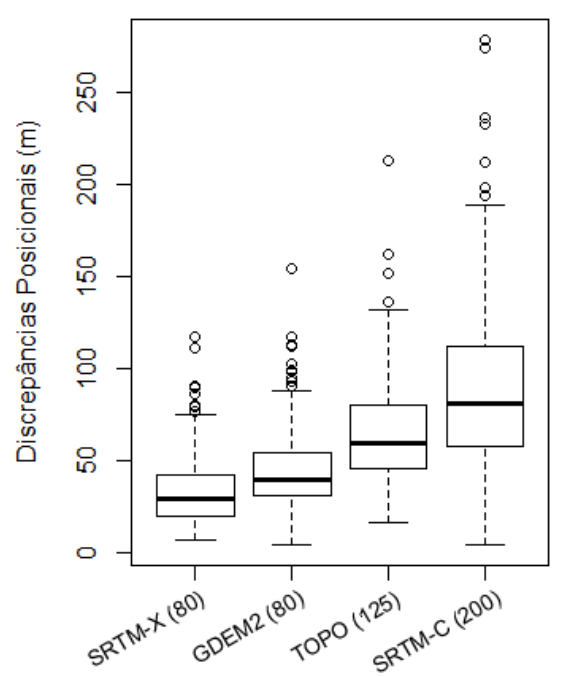

Figura 7: Boxplot das discrepâncias posicionais planimétricas dos MDSs testados. 
Tabela 2: Estatísticas descritivas das discrepâncias posicionais após a retirada de outliers.

\begin{tabular}{c|c|c|c|c|c|c|c|c|c|c}
\hline MDS & $\begin{array}{c}\text { Buffer } \\
(\mathbf{m})\end{array}$ & $\begin{array}{c}\mathbf{n}^{\circ} \\
\text { linhas }\end{array}$ & $\begin{array}{c}\text { RMS } \\
(\mathbf{m})\end{array}$ & $\begin{array}{c}\text { desv.pad. } \\
(\mathbf{m})\end{array}$ & $\begin{array}{c}\text { média } \\
(\mathbf{m})\end{array}$ & $\begin{array}{c}\text { min } \\
(\mathbf{m})\end{array}$ & $\begin{array}{c}\text { Q1 } \\
(\mathbf{m})\end{array}$ & $\begin{array}{c}\text { mediana } \\
(\mathbf{m})\end{array}$ & $\begin{array}{c}\text { Q3 } \\
(\mathbf{m})\end{array}$ & $\begin{array}{c}\mathbf{m a x} \\
(\mathbf{m})\end{array}$ \\
\hline SRTM-X & 80 & 162 & 31,8 & 12,0 & 29,4 & 7,2 & 19,6 & 27,9 & 38,2 & 62,7 \\
\hline GDEM & 80 & 162 & 43,6 & 14,7 & 40,9 & 4,6 & 30,3 & 38,2 & 50,8 & 77,1 \\
\hline TOPO & 125 & 171 & 65,9 & 21,4 & 62,2 & 16,6 & 45,9 & 58,2 & 78,5 & 126,8 \\
\hline SRTM-C & 200 & 167 & 90,1 & 36,5 & 82,2 & 4,4 & 57,3 & 78,3 & 106,8 & 176 \\
\hline
\end{tabular}

Com a amostra de discrepâncias sem a presença de outliers, aplicou-se o teste de normalidade Shapiro-Wilk, que apresentou valor de probabilidade não significativo a $0,1 \%$ para todas as amostras analisadas.

A Tabela 3 apresenta o resultado da avaliação da acurácia posicional planimétrica dos MDSs testados, utilizando o método do Buffer Duplo.

Tabela 3: Resultado da avaliação da acurácia posicional planimétrica dos MDSs.

\begin{tabular}{c|c|c|c|c}
\hline MDS & $\mathbf{n}^{\circ}$ linhas & $\mathbf{\%}(\mathbf{d m}<\mathbf{P E C})$ & $\mathbf{R M S}<\mathbf{E P} ?$ & Classificação \\
\hline SRTM-X & 162 & $100 \%$ & $\operatorname{sim}$ & Classe C 1:100.000 \\
\hline GDEM2 & 162 & $100 \%$ & $\operatorname{sim}$ & Classe C 1:100.000 \\
\hline TOPO & 171 & $99 \%$ & $\operatorname{sim}$ & Classe B 1:250.000 \\
\hline SRTM-C & 167 & $100 \%$ & $\operatorname{sim}$ & Classe C 1:250.000 \\
\hline
\end{tabular}

Analisando a Figura 7 e a Tabela 2 percebe-se uma grande variabilidade dos valores de discrepâncias posicionais planimétricas no modelo SRTM-C, sendo perceptível no valor da amplitude (cerca de $170 \mathrm{~m}$ ) e do desvio-padrão $(36,5 \mathrm{~m})$. Tal modelo teve a pior classificação da acurácia posicional sendo classificado como classe $C$ na escala 1:250.000. Já o modelo TOPO apresentou uma heterogeneidade de discrepâncias menor que o SRTM-C e maior que os MDS SRTM-X e GDEM2, sendo classificado como Classe B para a escala 1:250.000. Apesar dos modelos SRTM-X e GDEM2 apresentarem a mesma classificação da acurácia planimétrica (Classe B para a escala 1:100.000), o MDS SRTM-X apresenta uma menor variabilidade e menor magnitude dos valores de discrepâncias planimétricas $(\mathrm{RMS}=31,8 \mathrm{mn}$ e desviopadrão $=12 \mathrm{~m}$ ), quando comparado ao GDEM2 (RMS=43,6m e desvio-padrão=14,7m).

Conforme dito, o modelo Topodata foi gerado a partir de uma derivação do MDS SRTM banda $\mathrm{C}$ a partir de refinamentos utilizando interpolações por Krigagem. Apesar de não se esperar uma melhora da qualidade posicional, o modelo Topodata apresentou acurácia posicional melhor que o modelo SRTM banda C, conforme apresentado nas Tabelas 2 e 3. Entretanto, são necessários estudos mais aprofundados e experimentos específicos para avaliar a qualidade posicional do Topodata em relação ao SRTM banda C.

Tachikawa et al. (2011) avaliaram a acurácia posicional planimétrica do MDS Aster GDEM, versão 2, em 24 regiões do Japão realizando translações do GDEM sobre uma base japonesa de referência chamada GSI DEM, de resolução espacial de $10 \mathrm{~m}$. Ambas as bases foram reamostradas para células de 0,04 segundos de arco para fazer a comparação. Após, foi computado o desvio padrão das diferenças de altitude em cada deslocamento feito. $O$ deslocamento $\mathrm{X}$ e $\mathrm{Y}$ associado ao menor valor de desvio-padrão foi expresso como a discrepância horizontal, obtendo o valor da ordem de $7 \mathrm{~m}$ (com as componentes: $\mathrm{dx}=-0.13$ " e dy=-0.19"). A magnitude da resolução horizontal média no Aster GDEM foi da ordem de 0.601 segundos de arco (aprox. 18,5m), tendo valor máximo observado de 2,37 segundos de arco (aprox. 73m).

Segundo Rodriguez et al. (2005), o MDS SRTM tem como especificação técnica apresentar uma acurácia planimétrica menor que 20 metros ao nível de confiança de 90\%. Ainda segundo os 
autores, para a América do Sul a acurácia planimétrica obtida avaliando o SRTM com dados GPS é da ordem de 9 metros.

Percebe-se que os resultados obtidos neste trabalho diferem dos resultados citados para o GDEM e o SRTM. O RMS obtido para o SRTM-X $(31,8 \mathrm{~m})$ e o SRTM-C $(90,1 \mathrm{~m})$ apresentaram valores superiores à especificação técnica do modelo $(20 \mathrm{~m})$ e principalmente à avaliação dos dados na América do Sul (9m). O GDEM apresentou média de discrepâncias planimétricas quase 6 vezes maior que o obtido por Tachikawa et al. (2011) no Japão. Tais diferenças entre os resultados do SRTM e GDEM podem ser influenciadas pelas diferentes metodologias utilizadas na avaliação da acurácia posicional e principalmente pelas diferentes regiões de estudos.

\section{CONCLUSÕES}

Diante dos resultados obtidos, percebe-se o potencial e a viabilidade prática proporcionada pela metodologia proposta para avaliação da acurácia posicional planimétrica de MDE/MDS com o uso de feições lineares características do terreno, como linhas de cristas e talvegues.

De modo geral, os MDSs SRTM banda X e Aster GDEM versão 2 apresentaram classificação planimétrica Classe C para a escala 1:100.000, enquanto que os MDSs Topodata e SRTM banda C tiveram classificação planimétrica na escala 1:250.000 nas classes B e C, respectivamente.

Os resultados aqui expostos mostram a importância de se conhecer a qualidade posicional planimétrica de modelos de elevação. A grande maioria dos estudos sobre qualidade posicional em MDE/MDS de usos globais como os aqui utilizados focam apenas na avaliação da acurácia vertical. Estes trabalhos, como Miceli et al. (2011), citam que tais modelos podem ser utilizados em escalas de 1:100.000 e até 1:50.000, mas negligenciam a acurácia planimétrica de tais modelos, o que, como apresentado neste trabalho, pode ser pior que a acurácia vertical.

Em termos práticos, a metodologia proposta de avaliação da acurácia planimétrica apresentou-se mais viável do que a realizada em Tachikawa et al. (2011), onde o usuário tem que reamostrar o MDS e em seguida deslocar ou georreferenciar este sobre o MDS de referência.

Acredita-se que a metodologia proposta para avaliar MDSs com o uso de feições lineares características do terreno (linhas de cristas e talvegues) não será influenciada pelo procedimento de extração de linhas de hidrografias numéricas e linhas de cumeadas, já que o mesmo procedimento é aplicado tanto no MDS testado quanto no MDS de referência. Entretanto a resolução espacial dos MDSs utilizados é um fator que pode influenciar no resultado final. Tal metodologia avalia a acurácia posicional relativa, tomando como referência um outro MDS de melhor acurácia. Assim, deve-se ter um certo rigor na escolha do MDS de referência. Deste modo, sugere-se a aplicação da metodologia proposta em diferentes dados espaciais e regiões de estudos para uma melhor validação da metodologia.

Para futuros trabalhos deve-se investigar métodos para definir o número de feições lineares utilizadas na avaliação da acurácia posicional, bem como avaliar o padrão de distribuição espacial destas feições.

Por fim vale salientar que o caminho a ser seguido em pesquisas de acurácia posicional de MDE/MDS é a procura por metodologias que consigam avaliar conjuntamente a acurácia planimétrica e altimétrica destes modelos.

\section{REFERENCIAS BIBLIOGRÁFICAS}


Ariza, F. J. L., García Balboa, J. L., and Pulido, R. A. 2004. Casos Prácticos de Calidad En La Producción Cartográfica.

BRASIL. 1984. Decreto $N^{\circ} 89.817$ de 20 de Junho de 1984. Normas Técnicas Da Cartografia Nacional. Brasil.

Cruz, C. B. M., Barros, R. S., and Rabaco, L. M. L. 2012. "Planialtimetric Accuracy Evaluation of Digital Surface Model (DSM) and Digital Terrain Model (DTM) Obtained from Aerial Survey with LIDAR." ISPRS - International Archives of the Photogrammetry, Remote Sensing and Spatial Information Sciences XXXIX-B1 (1). Copernicus Publications: 45-48.

Dresch, G., and Santos, D. R. 2014. "Proposta de Uma Abordagem Híbrida Para Avaliação Da Acurácia Posicional Interna de Dados LiDAR Aerotransportados. In Anais do Congresso Brasileiro de Cartografia. Gramado, RS, Brasil.

DLR. 2015. STRM band-X parameter. German Aerospace Center. Disponivel em: $<$ http://www.dlr.de/eoc/en/desktopdefault.aspx/tabid-5515/9214_read-17716/>. Acessado em junho de 2015.

DSG. 2011. Especificação Técnica Para a Aquisição de Dados Geoespaciais Vetoriais (ET$A D G V)$. Brasil.

Egg, G. C. 2012. "Geração de Modelos Digitais de Superfície Compostos Utilizando Imagens Do Sensor PRISM/ALOS.” Universidade Federal de Viçosa.

Farr, T. G., Rosen, P.A., Caro, E., Crippen, R., Duren, R., Hensley, S., Kobrick, M. et al. 2007. “The Shuttle Radar Topography Mission.” Reviews of Geophysics 45 (2): RG2004.

Fernández, D. C. J., Valeriano, M. M., Zani, H., and Andrades Filho, C. O. 2013. "Extração automática de redes de drenagem a partir de modelos digitai de elevação." Revista Brasileira de Cartografia.

Höhle, J., and Höhle, M. 2009. "Accuracy Assessment of Digital Elevation Models by Means of Robust Statistical Methods." ISPRS Journal of Photogrammetry and Remote Sensing 64 (4): 398-406.

Höhle, J., and Pedersen, C. O. 2010. "A New Method for Checking the Planimetric Accuracy of Digital Elevation Models Data Derived by Airborne Laser Scanning." In Proceedings of the 9th International Symposium on Spatial Accuracy Assessment in Natural Resources and Environmental Sciences, University of Leicester, Leicester, UK, 253-56.

Li, Z., Zhu, Q. and Gold, C. M. 2005. Digital Terrain Modelling. Principles and Methodology. New York.

Maas, H. G.. 2002. "Methods for Measuring Height and Planimetry Discrepancies in Airborne Laserscanner Data.” Photogrammetric Engineering \& Remote Sensing 68 (9): 933-40.

Miceli, B. S., Dias, F. M., Seabra, F. M., Santos, P. R. A., and Fernandes, M. C.. 2011. "Avaliação vertical de Modelos Digitais de Elevação (MDEs) em diferentes configurações topográficas para médias e pequenas escalas.” Revista Brasileira de Cartografia 63 (1).

Montgomery, D. C., and Runger, G. C. 2002. Applied Statistics and Probability for Engineers. 
Mozas, A. T. C., Ureña, M. A., and Pérez, J. L. 2013. "Accuracy of Contour Lines Using 3D Bands." International Journal of Geographical Information Science 27 (12). Taylor \& Francis: 2362-74.

Reinoso, J. F. 2011. “An Algorithm for Automatically Computing the Horizontal Shift between Homologous Contours from DTMs." ISPRS Journal of Photogrammetry and Remote Sensing 66 (3): $272-86$.

Ribeiro, C. A. A. S., Soares, V. P., Oliveira, A. M. S., and Gleriani, J. M. 2005. "O Desafio Da Delimitação de Áreas de Preservação Permanente.” Revista Árvore 29 (2): 203-12.

Rodriguez, E., Morris, C. S., Belz, J. E., Chapin, E. C., Martin, J. M., Daffer, W., and Hensley, S. 2005. An Assessment of the SRTM Topographic Products. Pasadena, USA.

Santos, A. P. 2010. "Avaliação Da Acurácia Posicional Em Dados Espaciais Com O Uso de Estatística Espacial.” Universidade Federal de Viçosa.

Santos, A. P., Medeiros, N. G., Santos, G. R., and Rodrigues, D. D. 2015. "Controle de Qualidade Posicional Em Dados Espaciais Utilizando Feições Lineares.” Boletim de Ciências Geodésicas, v. 21, n. 2, p.233-250.

Sibson, R. 1981. "A Brief Description of Natural Neighbour Interpolation". Interpolating Multivariate Data. New York, John Wiley \& Sons, 21: 21-36.

Tachikawa, T., Kaku, M., Iwasaki, A., Gesch, D., Oimoen, M., Zhang, Z., Danielson, J., et al. 2011. ASTER Global Digital Elevation Model Version 2 - Summary of Validation Results.

Tveite, H., and Langaas, S. 1999. An Accuracy Assessment Method for Geographical Line Data Sets Based on Buffering. International Journal of Geographical Information Science 13 (1). Taylor \& Francis Group: 27-47.

Valeriano, M. M.. 2008. TOPODATA: Guia Para Utilização de Dados Geomorfológicos Locais. Vosselman, G. 2008. "Analysis of Planimetric Accuracy of Airborne Laser Scanning Surveys.” In International Archives of Photogrammetry and Remote Sensing, XXXVII: 99-104.

Recebido em março de 2015.

Aceito em setembro de 2015. 